\title{
Editorial
}

\section{Robust Control with Engineering Applications}

\author{
Tao Li, ${ }^{1}$ Baoyong Zhang, ${ }^{2}$ Zhiguang Feng, ${ }^{3}$ and Bochao Zheng ${ }^{1}$ \\ ${ }^{1}$ School of Information and Control, Nanjing University of Information Science \& Technology, Nanjing 210044, China \\ ${ }^{2}$ School of Automation, Nanjing University of Science and Technology, Nanjing 210094, China \\ ${ }^{3}$ Department of Mechanical Engineering, The University of Hong Kong, Hong Kong
}

Correspondence should be addressed to Tao Li; litaojia@nuist.edu.cn

Received 12 January 2014; Accepted 12 January 2014; Published 14 April 2014

Copyright (c) 2014 Tao Li et al. This is an open access article distributed under the Creative Commons Attribution License, which permits unrestricted use, distribution, and reproduction in any medium, provided the original work is properly cited.

Robust control is an important branch of control theory that explicitly deals with uncertainty in its approach to controller design. Over the past several decades, there has been an increasing interest in robust control. On one hand, uncertain parameters or disturbances exist inherently in the aeronautics and astronautics, advanced manufacturing, and other complex engineering systems. On the other hand, uncertain parameters or disturbances seriously affect the stability, accuracy, and reliability of underlying control systems. Therefore, robust control has become a challenging problem in international control filed, for example, $\mathrm{H}_{\infty}$ control, $\mathrm{H}_{2}$ control, guaranteed cost control (GCC), adaptive control (AC), variable structure control (VSC), antidisturbance control (ADC), fault-tolerant control (FTC), and so forth.

This special issue contain sixty-seven papers, which covers currently hot topics on robust control from theoretical methods to practical applications. Figure 1 shows their distribution about the topics. Moreover, we will summarize the typical papers about every topic.

$H_{\infty}$ Control. " $H_{\infty}$ control theory using in the air pollution control systems" by T. Yang et al. shows $H_{\infty}$ control theory for the air pollution control systems. " $H_{\infty}$ filter design for large-scale systems with missing measurements" by Y. Zhou et al. deals with the $H_{\infty}$ filter design problem for large-scale systems with missing measurements, where the occurrence of missing measurements is assumed to be a Bernoulli distributed sequence with known probability. "Delay-probability-distribution-dependent $H_{\infty}$ FIR filtering design with envelope constraints" by C. Peng et al. employs the information of the delay size and delay probability distribution and gives a novel delay-probability-distributiondependent filter design method.

$\mathrm{H}_{2}$ Control. " $\mathrm{H}_{2}$ control for continuous-time Markovian jump linear uncertain systems with partly known transition rates and quantization" by X.-G. Zhao et al. proposes sufficient conditions in terms of linear matrix inequalities for $\mathrm{H}_{2}$ control of Markov jump linear uncertain systems. "A novel approach to $l_{2}-l_{\infty}$ filtering design for T-S fuzzy systems with multiple time-varying delays" by X. Zhang et al. proposes the full-order and reduced-order filter design schemes for T-S fuzzy systems with multiple time-varying delays by using the free-weighting matrices method.

Guaranteed Cost Control. "Switching fuzzy guaranteed cost control for nonlinear networked control systems" by L. Cai et al. introduces a switching mechanism to handle the uncertainties of networked control systems and presents guaranteed cost controller design method. "Convergence guaranteed nonlinear constraint model predictive control via I/O linearization" by X. Kong et al. presents iterative quadratic program routine on the continuous-time system to guarantee its convergence.

Adaptive Control. "Characteristic modeling and control of servo systems with backlash and friction" by $\mathrm{Y}$. Wu et al. investigates an approach for modeling and adaptive control of servo systems with backlash and friction based on the characteristic model. "Robust adaptive PID control of robot manipulator with bounded disturbances" by J. Xu and L. Qiao gives two novel robust adaptive PID control schemes for 
robot manipulator with bounded disturbances and larger external disturbances can be tolerated by comparing with the existing adaptive PD control. "Global harmonic current rejection of nonlinear backstepping control with multivariable adaptive internal model principle for grid-connected inverter under distorted grid voltage" by Y. Yu et al. investigates the global harmonic current rejection problem of grid-connected inverter under distorted grid voltage and a multivariable adaptive state feedback control method is designed to guarantee the global stability of the closed-loop system.

Variable Structure Control. "Sliding sector-based variable structure control of continuous-time Markov jump linear systems subject to unknown transition rates" by Y.-M. Xue et al. presents a sufficient condition for variable structure control design based on sliding sector technique for a class of Markov jump systems with unknown transition rates.

Anti-Disturbance Control. "Active disturbance rejection with sliding mode control based course and path following for underactuated ships" by R. Li at el. investigates the path following problem of underactuated surface ship with uncertainties and external disturbances and active-disturbance-rejection control with sliding mode is provided to improve the performance of the closed-loop system. "Robust coordinated control algorithm for multiple marine vessels with external disturbances" by W. X. Liu et al. considers the coordinated control problem for multiple marine vessels with external disturbances and a robust coordinated control algorithm is given based on dynamic surface control method.

Fault-Tolerant Control. "Fault-tolerant control for civil structures based on LMI approach" by C. Qu et al. designs a filter to perform the fault detection and isolation and then forms a control strategy to achieve the fault-tolerant control. "Robust adaptive switching fault-tolerant control of a class of uncertain systems against actuator faults" by X.-Z. Jin deals with the fault-tolerant control problem for a class of linear time-invariant systems with time-varying actuator faults and uncertainties. "Fault-tolerant control in redundant inertial navigation system" by X. Dai studies the robust fault-tolerant control problem for the redundant inertial navigation system and an improved control algorithm which considers the unknown noise characteristics, model inaccuracies, and the drift factor to improve the control performance.

This special issue also includes riches of collections of engineering applications related to robust control theory, such as spacecraft and flight control, robots, power systems, networked systems, servo systems, autonomous underwater vehicles, and energy systems.

Of course, the selected topics and papers are not a comprehensive representation of the area of this special issue. Nonetheless, they represent the rich and much faceted knowledge that we have the pleasure of sharing with the readers.

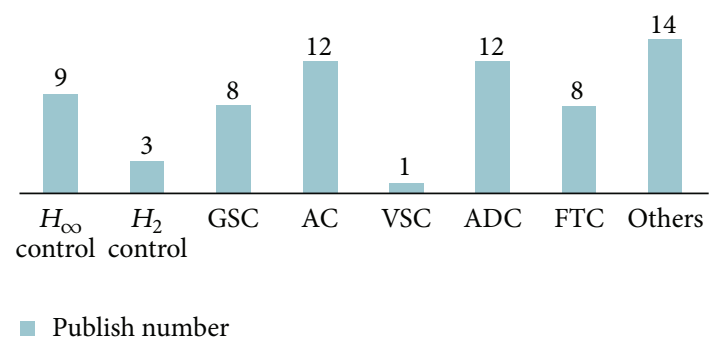

FIGURE 1

\section{Acknowledgments}

We would like to express appreciation to the authors for their excellent contributions and patience in assisting us. Finally, the fundamental work of all reviewers on these papers is also very greatly acknowledged.

Tao $\mathrm{Li}$

Baoyong Zhang Zhiguang Feng Bochao Zheng 


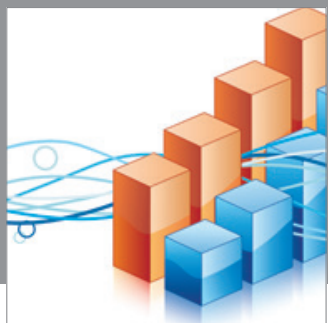

Advances in

Operations Research

mansans

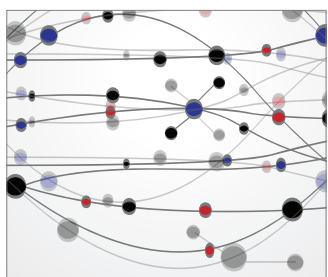

The Scientific World Journal
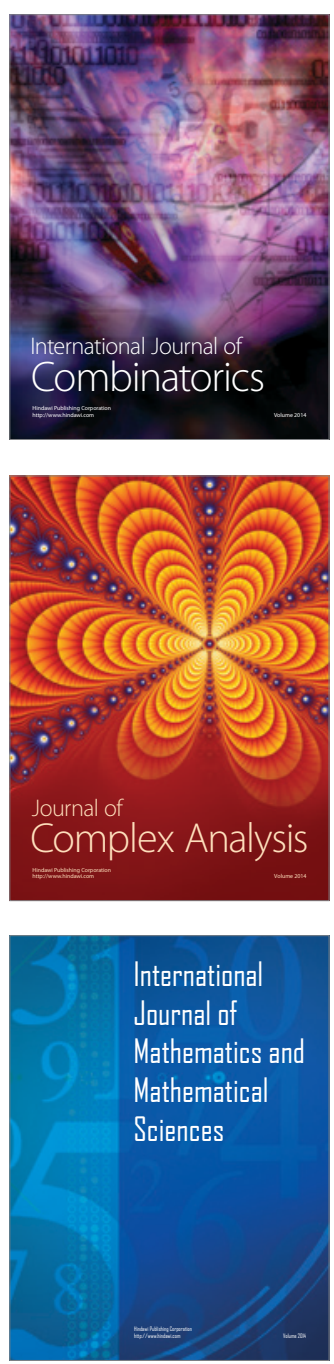
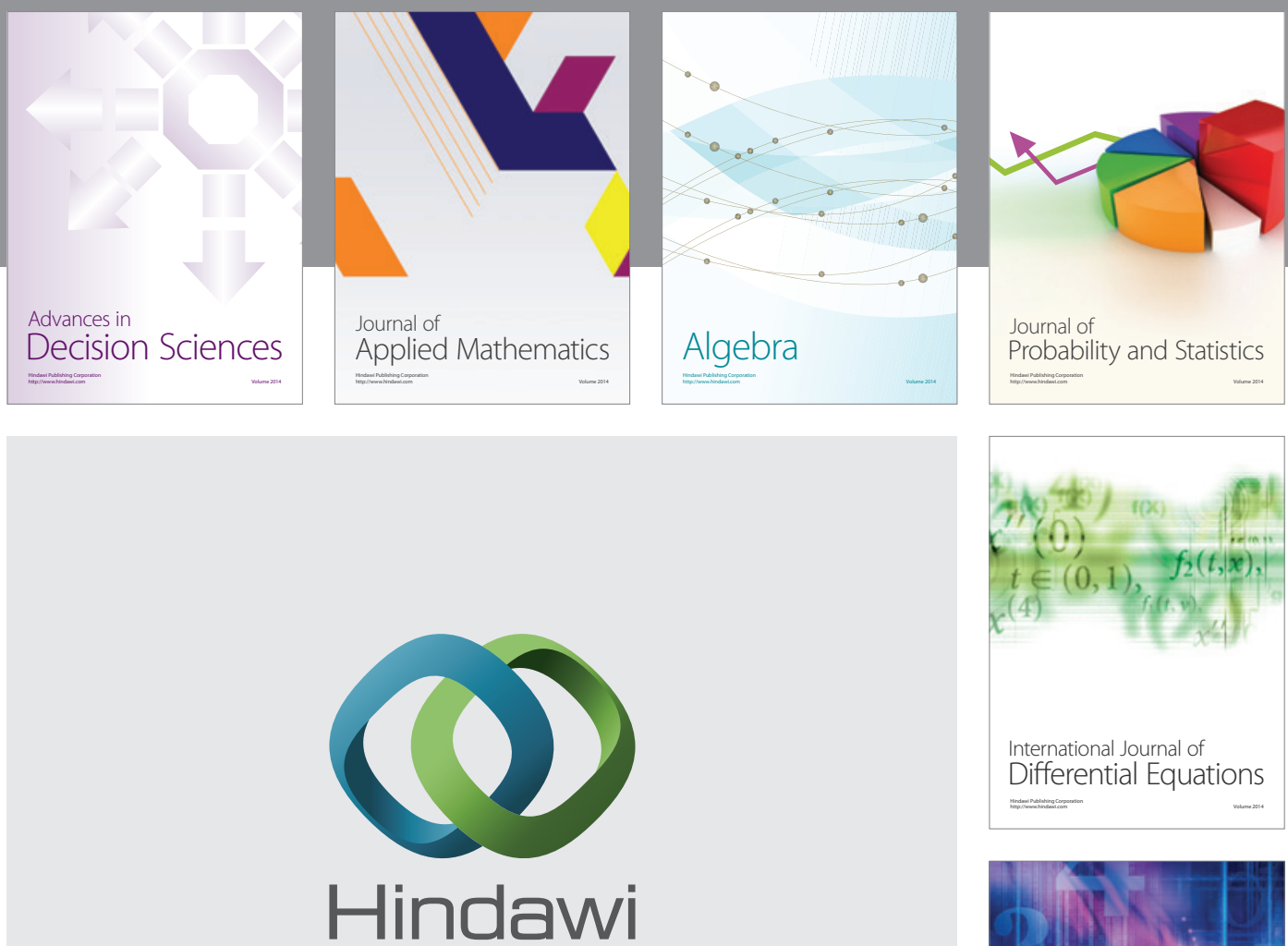

Submit your manuscripts at http://www.hindawi.com
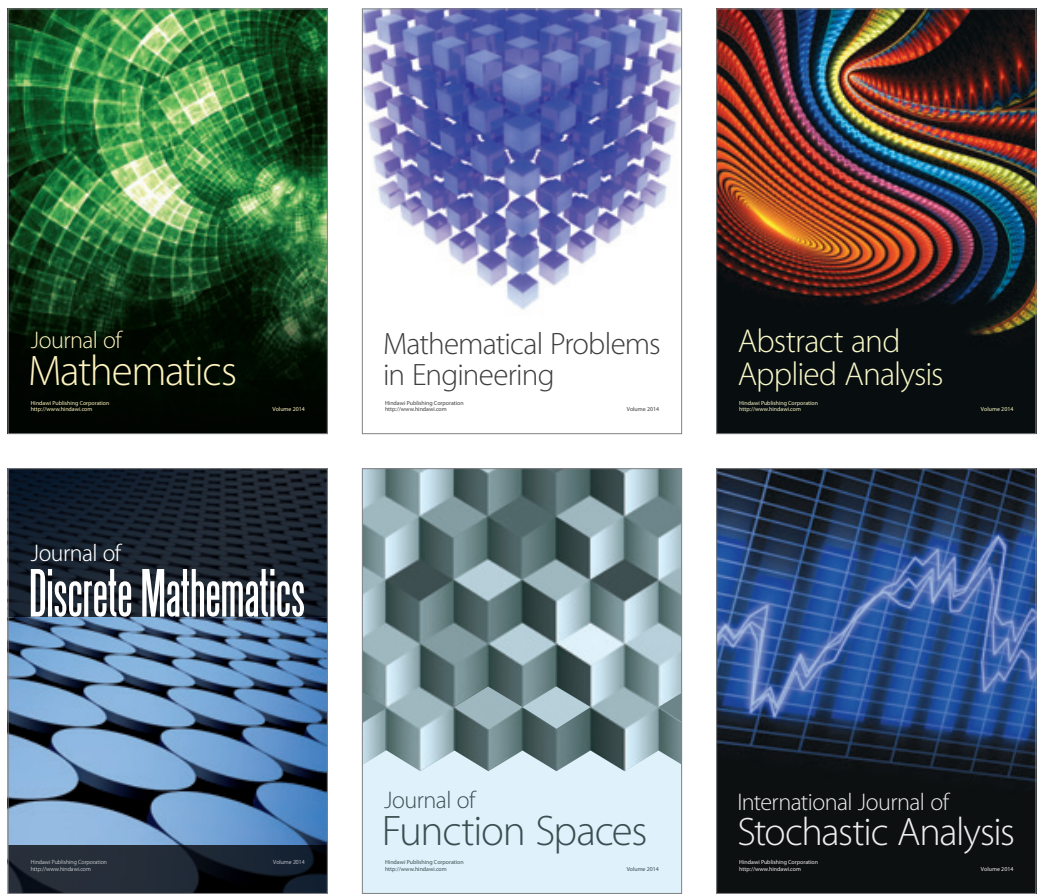

Journal of

Function Spaces

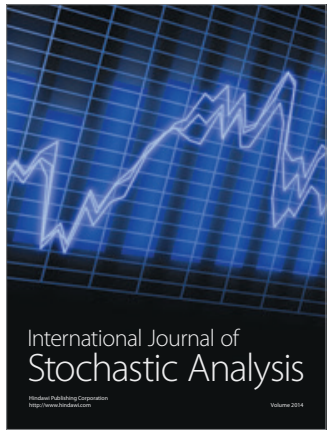

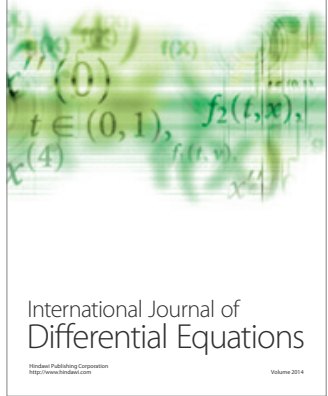
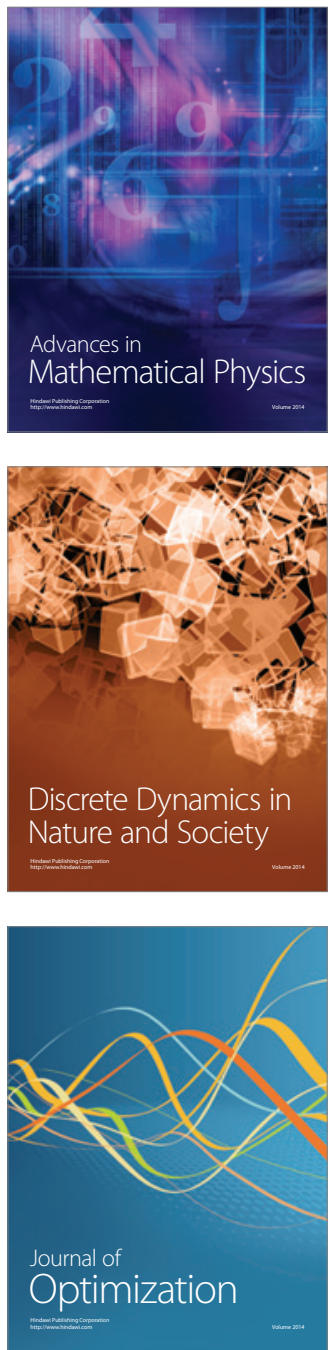